$>$ SPECIAL ISSUE ON UNDERSTANDING THE EFFECTS OF OFFSHORE WIND ENERGY DEVELOPMENT ON FISHERIES
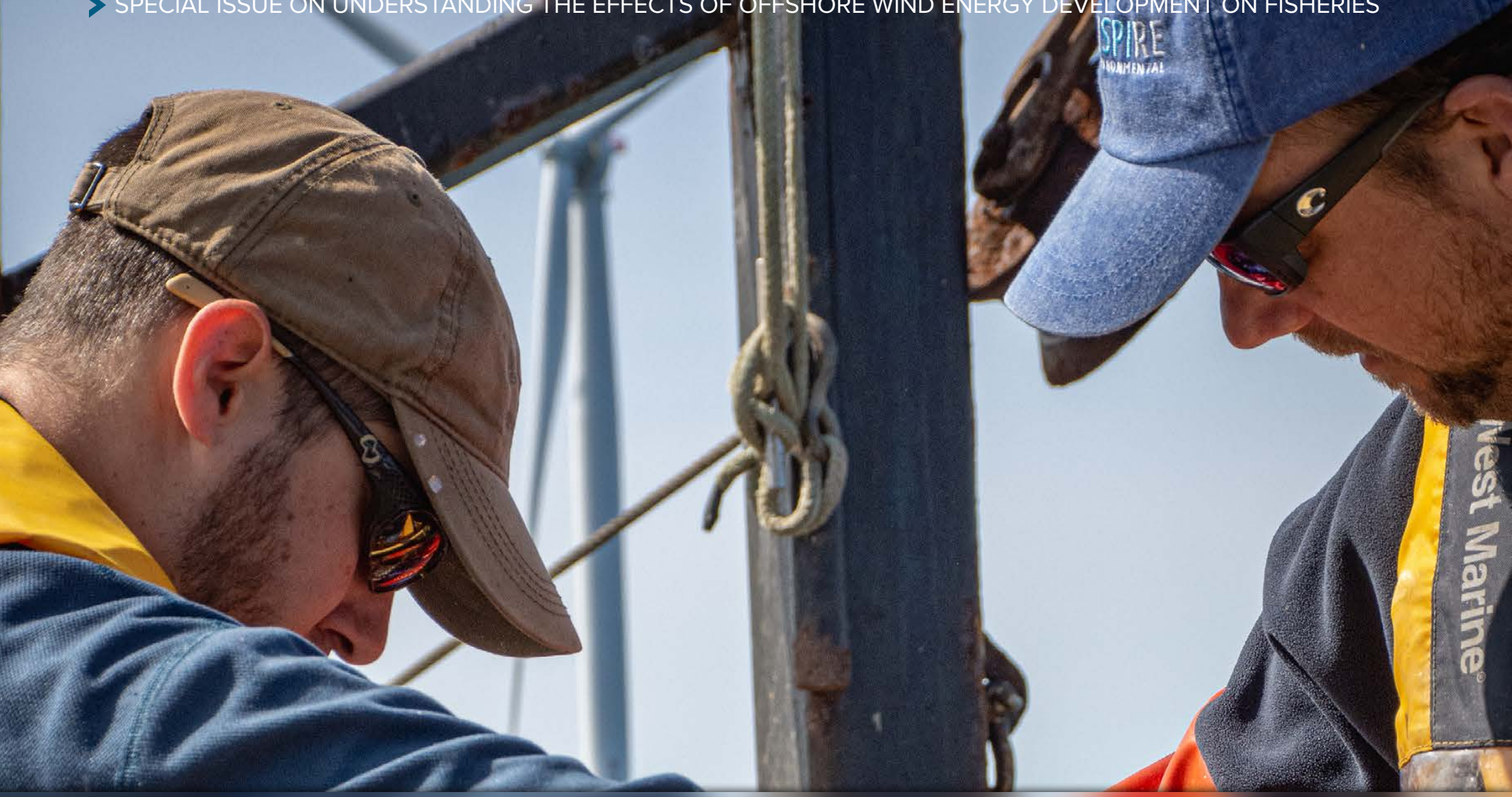

\title{
Effects of the Block Island Wind Farm on Coastal Resources LESSONS LEARNED
}

By Drew A. Carey, Dara H. Wilber, Lorraine B. Read, Marisa L. Guarinello, Matthew Griffin, and Steven Sabo
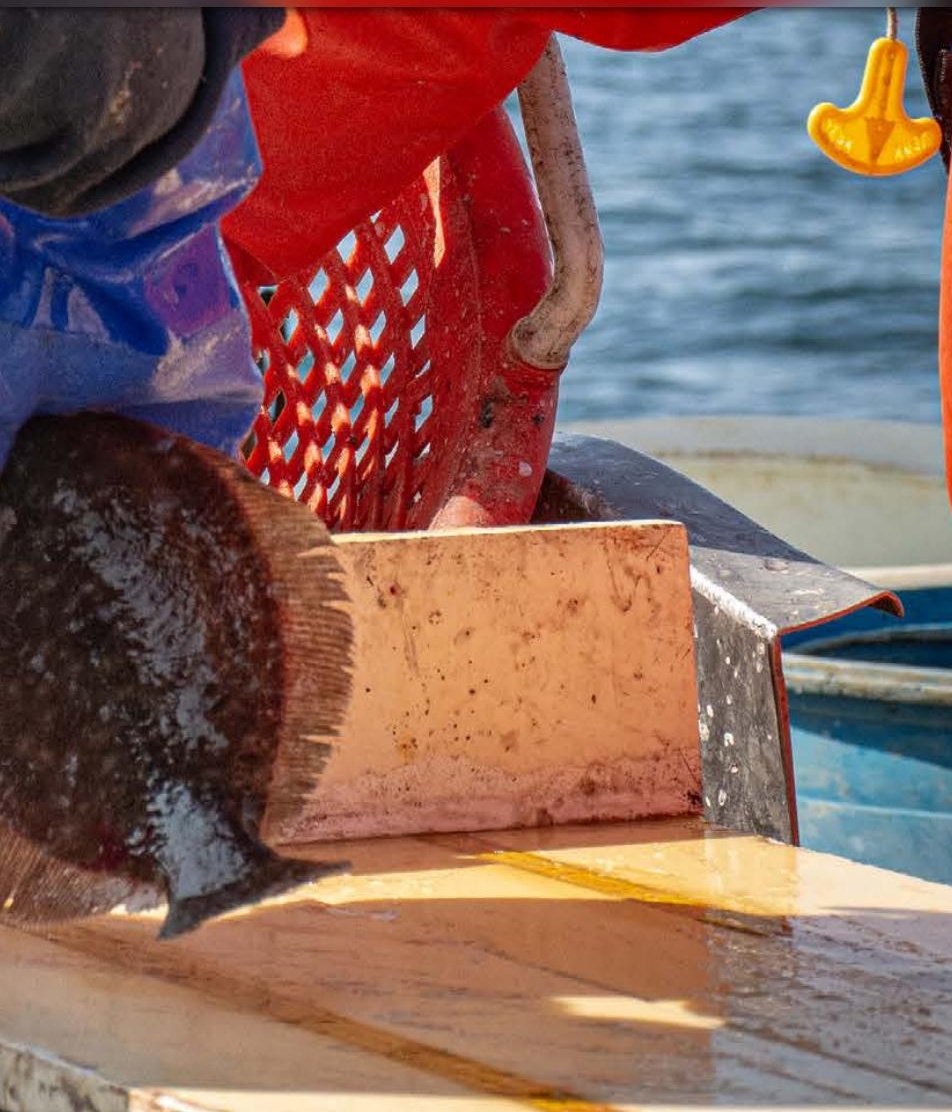
ABSTRACT. The Block Island Wind Farm, the first offshore wind farm in the United States, attracted intense interest and speculation about the effects of construction and operation on valuable coastal resources. Four studies designed to address the questions raised were conducted over seven years as a requirement of the lease agreement between the State of Rhode Island and the developer, Deepwater Wind Block Island. The objectives of the studies were to separate the effects of construction and operation on hard bottom habitats, demersal fish, lobster and crabs, and recreational boating from regional changes in conditions. Study elements included: early engagement with stakeholders (fishermen and boaters), adaptive monitoring based on data and stakeholder feedback, cooperative research with commercial fishermen, use of methods consistent with regional surveys, stratified random sampling within a before-after-control-impact (BACI) design, power analysis (when possible) to determine sample size, and multiple metrics to evaluate fish and fisheries resources. This combination of studies and analytical approaches evaluated multiple mechanisms by which potential effects could be detected. Lessons learned included practical guidance, for example, for collaborating with stakeholders and regional scientists to address concerns through adaptive monitoring, quantifying uncertainty associated with BACI contrasts, and evaluating the duration of a seasonal lobster survey. Applying these lessons can improve monitoring at proposed larger-scale offshore wind projects in the United States.

\section{INTRODUCTION}

The Block Island Wind Farm (BIWF) offers the first opportunity to assess the effects of offshore wind (OSW) development on coastal resources in the northeastern United States. "America's First Offshore Wind Farm" was constructed in 2015 and 2016 after an extensive scientific data-gathering and stakeholder vetting process (RICRMC, 2010). The pilot-scale project consists of five $6 \mathrm{MW}$ turbines located within the state waters of Rhode Island $5.3 \mathrm{~km}$ from Block Island. The turbines are within sight of communities that depend on tourism and recreational fishing (H. Smith et al., 2018) and that rely upon the project for electricity and grid connection (Russell et al., 2020). The BIWF is located close to rock reefs and intertidal habitats in an area with relatively low commercial fishing pressure (RICRMC, 2010). This unique juxtaposition of scale, location, resources, and user interests influenced the design of the studies described here (Figure 1).

The site selection and permitting process for the BIWF raised important ques-

FACING PAGE. The INSPIRE team conducts demersal-trawl cooperative research aboard F/V Virginia Marise at the Block Island Wind Farm. Photo credit: Steven Sabo ational users, adaptive monitoring based on data and stakeholder feedback, and cooperative research with commercial fishermen. Sampling was based on methods consistent with regional surveys (e.g., ASMFC, 2015; Bonzek et al., 2017) and included data on multiple metrics to evaluate fish and fisheries resources. Statistical considerations included stratified random sampling within a beforeafter-control-impact (BACI) design, using customized linear contrasts (e.g., Chevalier et al., 2019; Schad et al., 2020) and power analysis (when possible) to determine sample size.

Sampling designs were developed through an iterative collaborative process with state and federal regulators and stakeholders (commercial and recreational fishing and user groups) and direct meetings with local fishermen. Over 20 meetings of these groups and 15 meetings with fishermen resulted in a cooperative research design where fishermen identified suitable sampling locations, conducted the sampling with onboard scientists, and engaged in the interpretation of data. For each study, sampling began before construction in reference and potential-effect areas defined by their proximity to the planned installation area. The locations and sizes of these areas were scaled to the sampling method and expected effects; hence, they are distinctly named for each study (Table 1; Figure 2). Hard bottom habitat $(\mathrm{HBH})$ surveys of limited duration were conducted during three sampling periods over 15 months, with planned sampling at three and five years post-construction canceled with approval of state and federal regulatory agencies based on initial post-construction results. These surveys focused on $\mathrm{HBH}$ adjacent to the southern end of the wind farm using stratified random sampling, with post-construction locations adaptively added based on results of multibeam echosounder (MBES) mapping. Demersal trawl surveys began two years and eight months before construction, with monthly data collected from randomized trawl lines 
for seven years in three areas identified as suitable by commercial trawlers. Ventless lobster trap surveys began two years and two months before construction, with bimonthly data collected for seven years, in two locations with two areas each, which were identified by commercial lobstermen. Each year, trawl locations were randomly selected and revisited every two weeks May through October. Week-long recreational boating surveys that focused on identifying the locations of fishing activity began one month before construction and continued across four years. They were timed around one or two of the busiest recreational boating weekends each year, with data collected from three contiguous marine areas visible to a single observer on Block Island.

BACI study designs offer a powerful tool for detecting environmental impacts because they account for both temporal and spatial changes (Underwood, 1992; E. Smith et al., 1993; Stewart-Oaten and Bence, 2001). Natural spatial heterogeneity was acknowledged early in the design process and ameliorated by the inclusion of two reference areas for each survey. Sampling frequency was designed for each survey, tailored to provide the sampling intensity needed for examining potential impacts not only of wind farm operation but also of construction periods that included turbine installation and cable placement (Lindeboom et al., 2015; Dannheim et al., 2020).

\section{HARD BOTTOM HABITAT}

Physically complex and limited in distribution in Rhode Island Sound (RICRMC, 2010), HBH is critical for ecologically and economically important taxa such as American lobster (Wahle and Steneck, 1991), juvenile Atlantic cod (Gotceitas and Brown, 1993), and longfin squid (Griswold and Prezioso, 1981). Because these habitats provide stability and physical complexity, they are a focal point for regulatory conservation and mitigation, but prior to BIWF, few OSW farms have been located within $1 \mathrm{~km}$ of $\mathrm{HBH}$ (e.g., Wihelmsson and Malm, 2008; Roach et al., 2018). The BIWF was sited to avoid construction directly in $\mathrm{HBH}$, although one turbine was located

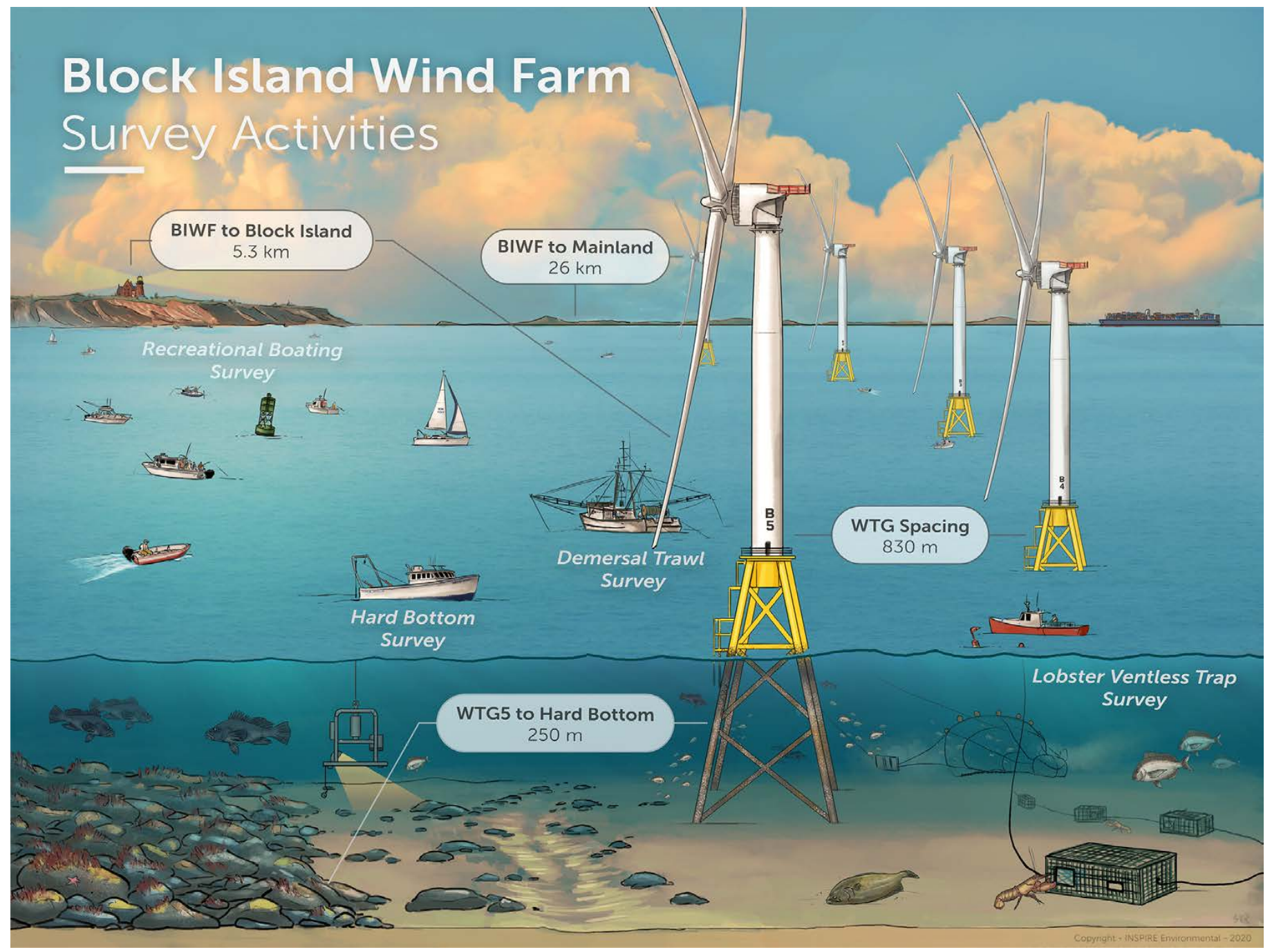

FIGURE 1. The first offshore wind farm in the United States, Block Island Wind Farm (BIWF) is unique in scale with five turbines $830 \mathrm{~m}$ apart. It is located near an island adjacent to natural reefs, an area where there is heavy recreational fishing use. Four studies related to fish and fisheries resources yielded important lessons on scale and duration for future monitoring efforts. WTG = wind turbine generator. 
close to $\mathrm{HBH}$ (Figure 2; HDR, 2018). Because $\mathrm{HBH}$ is present in several proposed US OSW areas, monitoring effects of construction within these habitats is important for potential mitigation of OSW development. Baseline, mid-, and post-construction surveys were designed to develop methodologies for assessing the abiotic and biotic features and distribution of $\mathrm{HBH}$ and OSW construction effects on these habitats (Guarinello and Carey, 2020) and to detect and evaluate disturbance and recovery from anchoring activity conducted proximal to these habitats (Guarinello et al., 2017).

\section{HBH Sampling Design}

Three surveys were conducted: (1) a baseline survey prior to construction in summer 2015, (2) a mid-construction survey in March 2016 to detect anchor effects in an area identified as at potential risk of impact, and (3) a post-construction survey in August 2016 prior to operation (Figure 2). For the baseline survey, a spatially balanced stratified random sampling design was used to select target stations for drop camera imaging within equal-area sampling grids (strata) in each monitoring area (North Reference, South Reference, Impact). Video transect locations were selected to provide broad coverage and to capture gradients in seafloor topography. For the March 2016 survey, coordinates of anchor locations and MBES data were used to position video transects

FIGURE 2. Survey footprints and timeline of four complementary multiyear studies conducted at the Block Island Wind Farm. and drop camera stations. The August 2016 post-construction survey determined if disturbance features identified in the March 2016 survey recovered and compared reference areas to the Impact Area. Video and drop camera survey locations were modified in real time to collect data at disturbance features detected in MBES data.

\section{HBH Analytical Methods}

Habitat data were evaluated using the Coastal and Marine Ecological Classification Standard (CMECS) recommended by federal regulators (FGDC, 2012), with modifications to reflect inferred physical stability (Guarinello and Carey, 2020). In addition to our study, a separate project recorded visual observations of construction activities during each phase of the project, and MBES monitoring was conducted on disturbance features from anchors and jackup barges in soft sediments at six-month intervals from May 2016 to May 2017 to document physical recovery (HDR, 2018).

\section{Lessons Learned from}

\section{HBH Sampling Design}

The study design used several approaches to capture physical and biological recovery from habitat disturbance, includ-

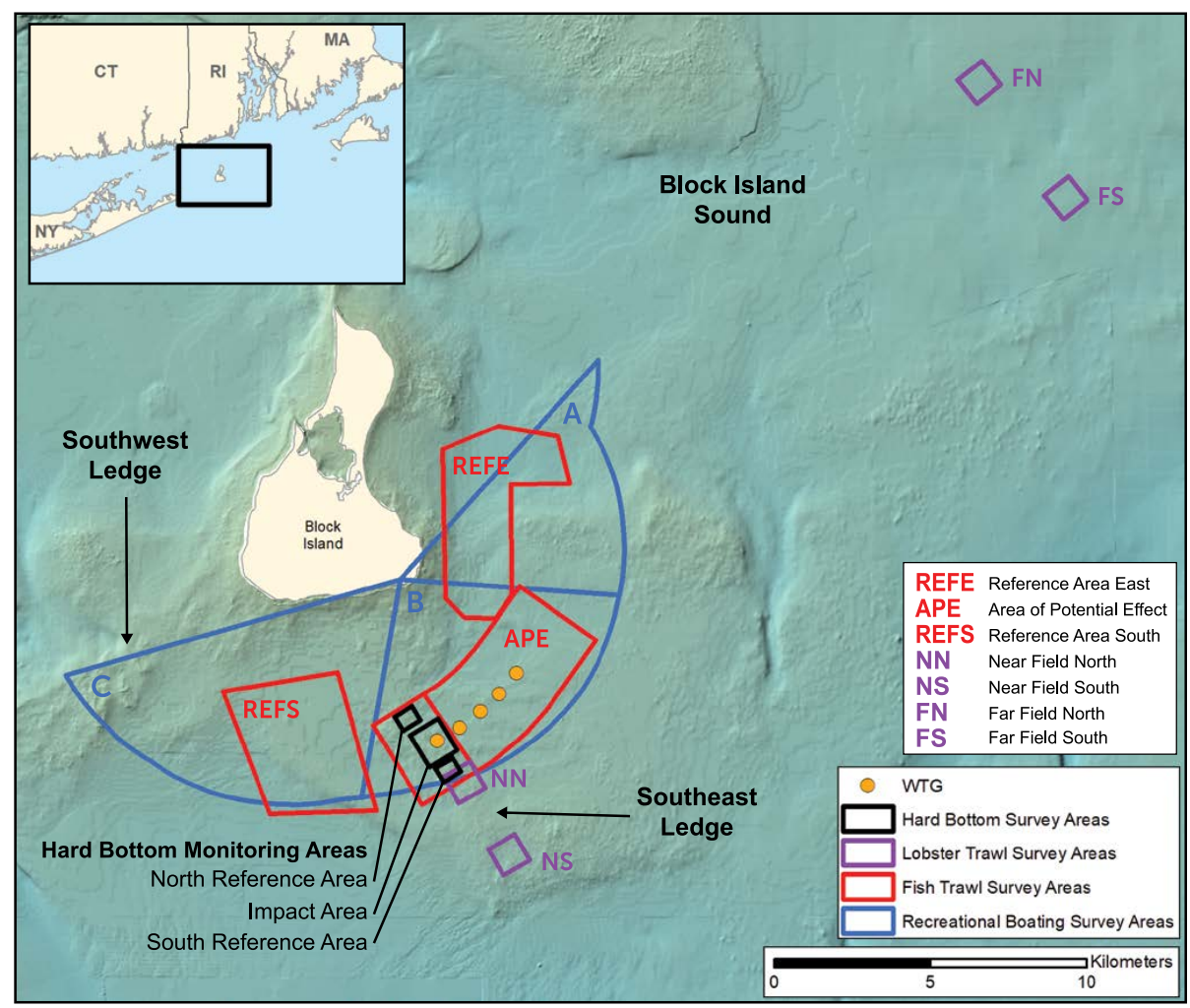

Monthly Demersal Trawl Survey Begins October 2012
Recreational Boating Survey Begins June 2015

Hard Bottom Survey Begins August 2015
Ventless Lobster Survey Ends October 2019

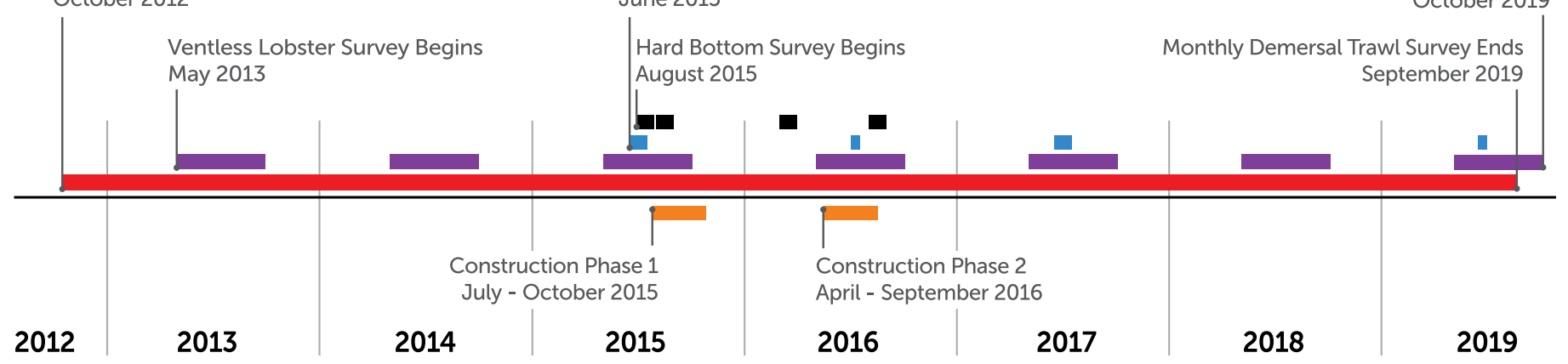


ing MBES time-series mapping and randomized analysis of biotic cover of disturbed soft bottom habitats as well as non-random MBES mapping of postconstruction conditions with directed high-resolution imagery of disturbed and undisturbed features. By adaptively monitoring (i.e., directing video and camera locations to disturbed habitat identified by MBES), the probability of characterizing recovery was increased compared to the use of as-built anchor locations or random sampling. The rate of physical seafloor recovery in mobile sand sediments (surface returning to baseline conditions) can be related to seabed mobility, with areas of higher seafloor energy with finer sand recovering more quickly (K. Smith and McNeilan, 2011; HDR, 2018). However, biological recovery of $\mathrm{HBH}$ may be inversely related to seabed mobility (Wilhelmsson and Malm, 2008). Two studies evaluated recovery of the seafloor from physical disturbance that resulted in distinct furrows due to anchor drag (HDR, 2018; Guarinello and Carey, 2020). Some furrows (drag marks) were unchanged in MBES signature over time due to the presence of boulders lining the furrows (Figure 3). Biological growth on the boulders returned in less than a year, with mean percent cover increasing from 10\% to 62\% in August 2016 compared to March 2016 (Guarinello et al., 2017). MBES surveys in October 2016 and May 2017 noted that 32\% of the drag marks created in soft sediment without boulders in 2015 had fully recovered physically by May 2017 (HDR, 2018). Use of multiple survey approaches revealed the clear contrast in the response of mobile habitats to construction disturbance (return to baseline profile) compared to relocated boulders (return to baseline biological cover, but similar physical profile).
Modification of CMECS to include physical habitat stability proved a useful tool for interpreting video data, and combining this approach with adaptive sampling could be an effective methodology for studies of hard bottom effects at other OSW projects that involve relocated boulders (Guarinello and Carey, 2020).

\section{DEMERSAL FISH}

Stakeholder feedback from the permitting process identified potential effects on demersal fish, lobster, and sport fish as primary concerns (RICRMC, 2010). The demersal trawl surveys were designed in conjunction with ventless trap surveys (see below) to measure how the fish and invertebrate community near the BIWF was affected by construction and operation. The study area had limited scientific fish sampling data from regional surveys so the usage of the site by fish was poorly known (RICRMC, 2010).

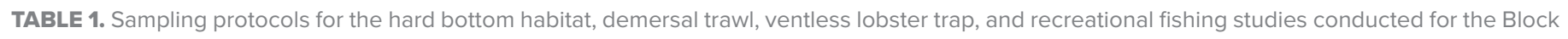

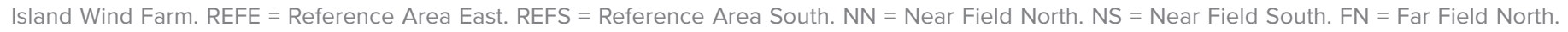
FS = Far Field South.

\begin{tabular}{|c|c|c|c|c|c|}
\hline $\begin{array}{l}\text { SURVEY } \\
\text { TYPE }\end{array}$ & $\begin{array}{c}\text { IMPACT (I) AND } \\
\text { REFERENCE (R) } \\
\text { AREA } \\
\text { TERMNOLOCY }\end{array}$ & SAMPLING PROTOCOL & $\begin{array}{c}\text { REPLICATION } \\
\text { WITHIN EACH } \\
\text { AREA }\end{array}$ & $\begin{array}{c}\text { TOTAL NUMBER OF } \\
\text { SAMPLES }\end{array}$ & $\begin{array}{l}\text { PARAMETERS } \\
\text { ANALYZED }\end{array}$ \\
\hline $\begin{array}{l}\text { Hard } \\
\text { Bottom } \\
\text { Habitat }\end{array}$ & $\begin{array}{l}\text { - I: Impact Area } \\
\text { - R: North and South } \\
\text { Reference Areas }\end{array}$ & $\begin{array}{l}\text { - Pre-construction in } \\
\text { reference and impact areas } \\
\text { (summer 2015) } \\
\text { - Mid-construction to detect } \\
\text { anchor features in impact area } \\
\text { (March 2016) } \\
\text { - Post-construction in } \\
\text { reference and impact areas } \\
\text { (summer 2016) }\end{array}$ & $\begin{array}{l}\text { - Three drop } \\
\text { camera images } \\
\text { per station }\end{array}$ & $\begin{array}{l}\text { - } 2 \mathrm{~km}^{2} \text { area of } \\
\text { bathymetry, backscatter, } \\
\text { side-scan sonar } \\
\text { - } 47 \text { towed video transects } \\
\text { (ranging from } 54 \text { to } \\
1,049 \text { m in length) } \\
\text { - } 130 \text { drop camera stations } \\
\text { - } 30 \text { single image stations } \\
\text { at anchor features }\end{array}$ & $\begin{array}{l}\text { - Classifiers from the } \\
\text { CMECS substrate and } \\
\text { biotic components }\end{array}$ \\
\hline $\begin{array}{l}\text { Demersal } \\
\text { Trawl }\end{array}$ & $\begin{array}{l}\text { - I: Area of Potential } \\
\text { Effect (APE) } \\
\text { - R: REFE and REFS }\end{array}$ & $\begin{array}{l}\text { - Monthly, October 2012- } \\
\text { September } 2019\end{array}$ & $\begin{array}{l}\text { - Two random } \\
\text { trawls per } \\
\text { month }\end{array}$ & - 497 trawls & $\begin{array}{l}\text { - Fish and invertebrate } \\
\text { catch rates and sizes } \\
\text { - Fish condition } \\
\text { - Fish diet composition } \\
\text { - Fish stomach fullness }\end{array}$ \\
\hline $\begin{array}{l}\text { Ventless } \\
\text { Lobster Trap }\end{array}$ & $\begin{array}{l}\text { - I: Near Field } \\
\text { (areas NN and NS) } \\
\text { - R: Far Field } \\
\text { (areas FN and FS) }\end{array}$ & $\begin{array}{l}\text { - Twice monthly, May to } \\
\text { October, 2013-2019 }\end{array}$ & $\begin{array}{l}\text { - Six fixed trawls } \\
\text { per year }\end{array}$ & • 1,718 trawls $(10,251$ traps) & $\begin{array}{l}\text { - Lobster catch rates } \\
\text { and sizes } \\
\text { - Ovigery rates } \\
\text { - Shell disease } \\
\text { - Cull status } \\
\text { - Bycatch rates and sizes }\end{array}$ \\
\hline $\begin{array}{l}\text { Recreational } \\
\text { Fishing }\end{array}$ & $\begin{array}{l}\text { - I: Zone B } \\
\text { - R: Zones A and C }\end{array}$ & $\begin{array}{l}\text { Week-long surveys conducted: } \\
\text { - Pre-construction } \\
\text { (June and July 2015) } \\
\text { - Mid-construction (July 2016) } \\
\text { - Operation (June and July 2017, } \\
\text { June 2019) }\end{array}$ & $\begin{array}{l}\text { Four } 30-\text { minute } \\
\text { survey blocks, } \\
\text { three times } \\
\text { a day for } \\
\text { one week }\end{array}$ & $\begin{array}{l}324 \text { total survey blocks: } \\
\text { - Pre }(n=132) \\
\text { - Mid }(n=60) \\
\text { - Operation }(n=132)\end{array}$ & $\begin{array}{l}\text { - Vessel counts, activity, } \\
\text { and location }\end{array}$ \\
\hline
\end{tabular}




\section{Trawl Sampling Design}

Baseline, construction, and operational sampling with a demersal otter trawl occurred monthly over seven years near the wind farm in an area of potential effect (APE) and in two nearby reference areas (REFE and REFS; Figure 2). Habitat characteristics (depth and substrate composition) were similar in all areas. Gear and sampling protocols consistent with those used by the longterm, biannual demersal trawl survey in Rhode Island Sound (Bonzek et al., 2017) allowed comparison with historical data and broadened the spatial context of the study. Cooperative research using a commercial fishing vessel, captain, and crew, with scientists onboard to process the catch, promoted communication with the local fishing community that facilitated adaptive monitoring in response to fishermen's concerns.

Fish populations naturally exhibit large variability in abundance, which can weaken even a robust BACI approach to assessing wind farm impacts based on catch statistics alone (Lindeboom et al., 2015; Methratta, 2020). Recreational fishermen were concerned about lack of information regarding effects on prey species. Therefore, additional metrics (fish condition, stomach fullness, and prey composition) were included for flounders, hakes, and cod. An example of adaptive monitoring was the inclusion of black sea bass in the diet study component during the seventh year of sampling in response to an industry concern that juvenile lobsters were being consumed by these fish. Select preliminary demersal trawl results for the first six years are provided here to illustrate lessons learned from this study (data processing for the seventh year is ongoing).

\section{Trawl Analytical Methods}

Statistical methods focused on estimating the 95\% confidence intervals (95CI) around measures of change described by pre-specified contrasts. BACI interaction contrasts described the spatial differences (APE versus each reference area) in mean abundance between the baseline and operation time periods. A similar interaction contrast was used to describe the spatial differences in mean abundance between baseline and the two construction periods. Catch data (average monthly catch per trawl) were modeled in R (R Core Team, 2019) as a function of area and year with negative binomial generalized linear models (GLMs) with a loglink. Monte Carlo confidence intervals were constructed for the contrasts using 5,000 draws from the multivariate distribution of model coefficients. Diet composition data, stomach fullness indices, and fish condition indices calculated from length-weight regressions were graphed to depict spatial and temporal changes, and analyses of variance (ANOVAs) were conducted when sufficient data were available. Multivariate analysis included spatial and temporal comparisons of fish and invertebrate community composition and prey assemblage composition using non-metric multidimensional scaling (nMDS) and analysis of similarities (ANOSIM) based on the Bray-Curtis distance metric (Clarke et al., 2014).

\section{Lessons Learned from}

\section{Trawl Sampling Design}

Multiple metrics (catch rates, assemblage composition, condition, diet composition, and stomach fullness) were useful

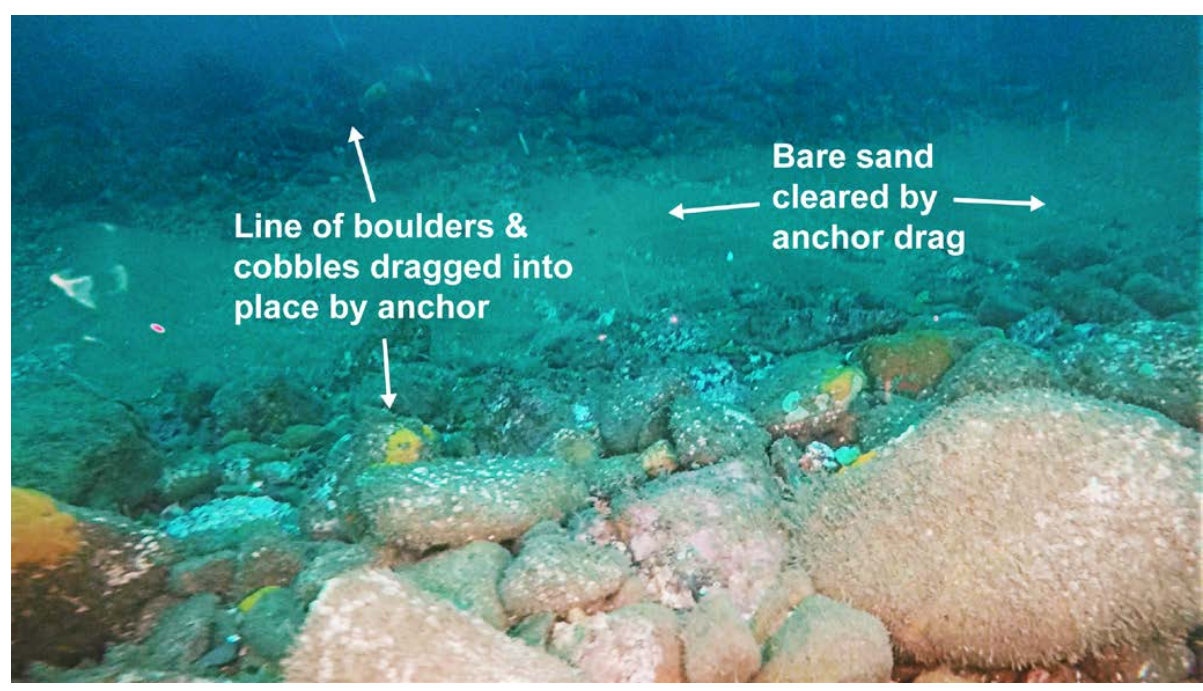

FIGURE 3. Anchor furrow imaged by towed video during the March 2016 post-construction survey. to assess potential wind farm effects and provided a more complete understanding of how turbine foundations function as shelter and colonization resources. For instance, although spatial and temporal differences in abundances were evident, results for the interaction contrasts of the catch rate models often did not reflect an impact statistically different from zero (i.e., where 95CIs excluded zero). As an example, the longfin squid BACI contrast between APE and REFE had an expected 82 fewer squid per tow (0.003 fewer squid per $\mathrm{m}^{2}$ ) during the operation period compared to the baseline time period with 95CI [-341, 109]. The width of this statistically nonsignificant confidence interval illustrates how the inherently large variance in catch data results in low statistical power for anything but large effect sizes. Notably, this survey collected 53,860 squid using 426 trawls over six years. Longfin squid distributions also provide a good example of a species with consistent spatial trends in catch throughout the study, with consistently higher abundances at the REFE than in the APE or REFS (Figure 4). In contrast, black sea bass abundances dramatically increased (over 1,200\%) between baseline and operation periods at the APE, while changes at the referHowever, the interaction contrasts were ence areas were more modest (Figure 4). 
not statistically significant for either REFE (95CI of $-328,21$ ) or REFS (95CI of $-338,5)$, demonstrating the importance of not relying solely on statistical outcomes when evaluating potential wind farm effects. Black sea bass is a structureseeking species that prefers complex bottom habitat, as provided by the turbine foundations (Guida et al., 2017).

The preliminary BACI analyses comparing two years of the baseline period to two years of wind farm operation revealed the value of two reference areas and comparable regional studies that provided context. For instance, conclusions varied in some cases depending on the reference area used for comparison. Most commonly, similar changes in abundance occurred at both the APE and at least one reference area between the baseline and operation periods. In other cases, consistent results suggested a regional trend, such as declining abundances of Atlantic herring, alewife, and butterfish in all areas over six years and in regional surveys (Wilber et al., 2020a). Use of a single reference area in future studies may not adequately account for the role of spatial variability for a highly stochastic metric such as fish and invertebrate catches.

Diet composition was an important aspect of survey design, providing a window into wind farm effects on trophic relationships of importance to user groups. Lobsters were not found in the stomachs of black sea bass, although crabs were a common prey item for them. Ten times more winter flounder had blue mussels in their diets during the operation period, coinciding with the concentration of blue mussels, an early colonizer of the turbine foundations (HDR, 2020), in relatively large numbers in the APE and the REFS (Wilber et al., 2020a).

Because the timing and scale of construction and operation were unknown during study design, the BACI design with continuous monthly sampling for the study duration was crucial. Monthly abundance data during the discontinuous construction phases were compared to baseline data and regional data from the same months. The short time periods for the construction activities limited statis- tical power for the interaction contrasts on some of the additional metrics; therefore, analyses included graphical comparisons of stomach fullness indices and prey composition in the diets of focal predators among areas. Depictions of spatial and temporal trends in these metrics can inform assessment of potential construction effects; thus, the inclusion of these metrics in future monitoring of other OSW projects should be considered.

\section{LOBSTERS AND CRABS}

\section{Ventless Trap Sampling Design}

Ventless trap surveys were conducted twice per month during lobster season (May to October) over seven years, ending in October 2019 (Table 1). Preliminary survey results are provided here to illustrate lessons learned and are based on the first six years of the study; data processing for the seventh year is ongoing. Sampling was conducted in two potential impact areas near the wind farm, Near Field North (NN) and Near Field South (NS), and two reference areas approximately $22 \mathrm{~km}$ distant from the wind farm,
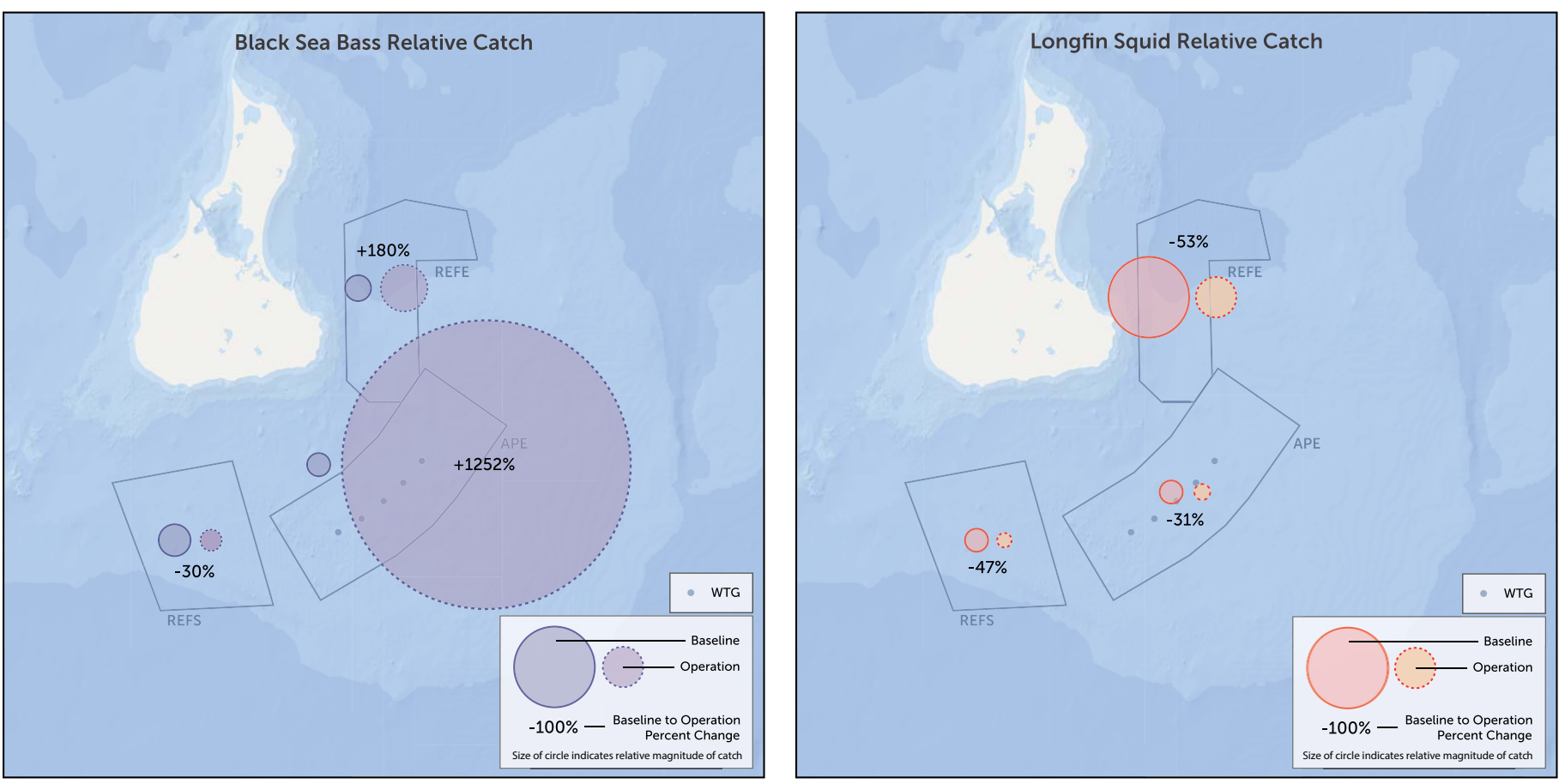

FIGURE 4. Relative catches of longfin squid and black sea bass in the demersal trawl survey for the baseline and turbine operation periods in the area of potential effect (APE) and reference areas (REFE and REFS). Circle size indicates relative magnitude of average catch; percentages indicate the changes between baseline and turbine operation periods for each area. 
Far Field North (FN) and Far Field South (FS) (Figure 2). The sampling design was influenced by the results of a power analysis that used regional catch data for 2006-2012 from a ventless trap survey (ASMFC, 2015) to identify background variability and illustrate the relationship between sampling effort and precision of catch estimates. The final design integrated these sample-size estimates with additional input from lobstermen, including steps to mitigate gear loss (trawl orientation, number of traps per trawl), soak time to allow for adequate trap fill, and fine-tuning site selection to reduce user conflicts (existing gill nets and tow tracks). The design also incorporated the Rhode Island lobster industry request that the survey include at least one vented trap per six-trap trawl for comparison with commercial fishing efforts and to reduce a potential bias of trap saturation by juveniles and crabs.

Lobster size, female reproductive status, shell disease, and claw loss (cull status) also were monitored. Female reproductive status was noted to identify locations with favorable conditions for egg development and hatching and to examine potential effects of BIWF construction and/or operation. The increase in shell disease prevalence in Rhode Island Sound since the late 1990s (Castro and Somers, 2012) and claw loss can be indicators of environmental stress. Claw loss also creates individuals that are less valuable to the fishery than intact lobsters. Catch rates and individual sizes were also evaluated for several bycatch species that were developing or established as commercial and recreational fisheries in the area, such as Jonah crab (Cancer borealis), rock crab (Cancer irroratus), and black sea bass (Centropristis striata).

\section{Ventless Trap Analytical Methods}

Similar to the demersal trawl survey, statistical methods focused on estimating the 95CI around measures of change described by pre-specified contrasts. Lobster catch data (average annual catch per trap [CPUE] for the six-trap trawls) were modeled in $\mathrm{R}$ as a function of area and year with normal GLMs and a log-link. Models for other metrics, for example, proportion ovigerous, shell disease, and claw status, were constructed similar to catch data, but with binomial GLMs and a logit-link.

\section{Lessons Learned from Ventless Trap Sampling Design}

Assessing multiple metrics provided a means to evaluate several potential mechanisms of effect. The number of years surveyed allowed comparison with regional trends. Average lobster catches were lower during the operation period both Near Field (difference of -0.6 , 95CI $[-1.0,-0.3]$ ) and Far Field (difference of -0.5 , 95CI $[-0.9,-0.2])$, reflecting a trend of declining catches throughout the region (Wilber et al., 2020b). Spring (late-stage eggs) ovigery rates increased between the baseline and operation time periods to a greater extent in the Far Field (difference of $25 \%, 95 \mathrm{CI}[11 \%, 38 \%]$ ) than near the wind farm where ovigery rates were highly variable (difference of 7\%, 95CI
[-27\%, 38\%]). Use of two sampling blocks in both the Near Field and the Far Field (Figure 2) provided a better understanding of spatial variation in late-stage, ovigerous female distributions; for example, ovigery rates at NS increased 14\% between the baseline and the operation time periods compared to a decrease of less than $1 \%$ at $\mathrm{NN}$.

Potential construction effects were examined by comparing estimates between months in which construction occurred to the same months during the baseline period (Figure 2). Bimonthly sampling provided sufficient data to determine that lobster catches were significantly higher near the wind farm during Phase I construction (difference of 0.5 , 95CI [0.1, 1.0], Figure 5; Wilber et al., 2020b), and significantly higher everywhere during Phase II (difference of 1.1 in the Near Field, 95CI $[0.7,1.5]$ and 4.5 in the Far Field, 95CI [4.1, 4.9]), a period during which high catches were observed throughout the region as corroborated by Rhode Island and Massachusetts state surveys (Wilber et al., 2020b).

During the last survey of each year (late October), lobster catch rates at the Near Field areas were often still near their annual high, while catch rates in Far Field areas were near zero (FN) or between $20 \%$ and $50 \%$ of the annual high (FS). This seasonal trend in catches declining earlier with increasing proximity to the mainland is consistent with seasonal offshore movement as nearshore water temperatures decline (Goldstein and Watson, 2015). Annual lobster catches were consistently higher at the Far Field areas throughout all years of sampling. In hind-

Lobster Relative Catch Per Unit Effort
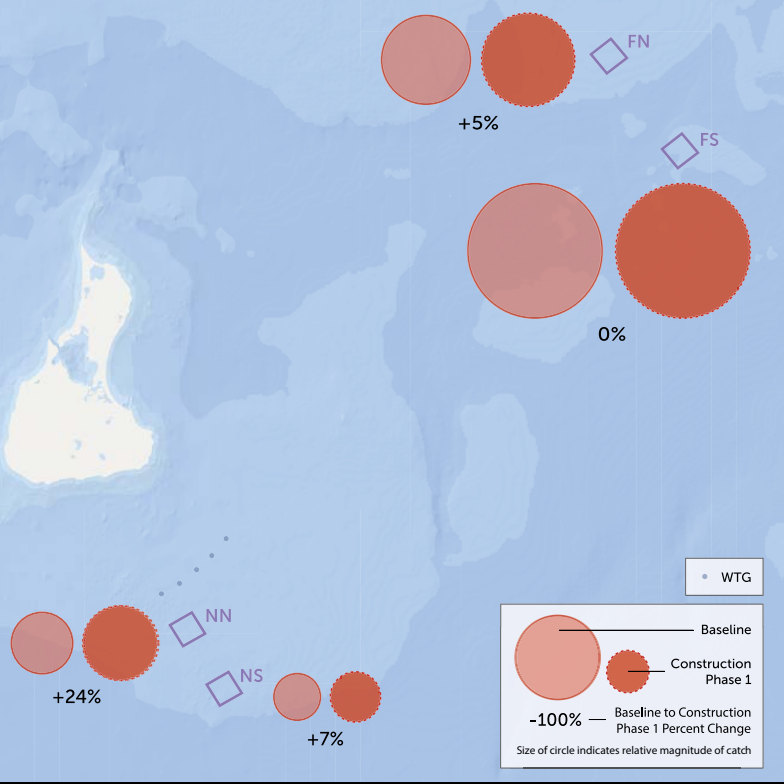

FIGURE 5. Relative catches of lobster in the ventless trap survey for the baseline and turbine installation periods at two sampling areas near the wind farm (NN and NS) and two far-field areas (FN and FS). Circle size indicates relative magnitude of average catch; percentages indicate the changes between baseline and turbine installation for each area. 

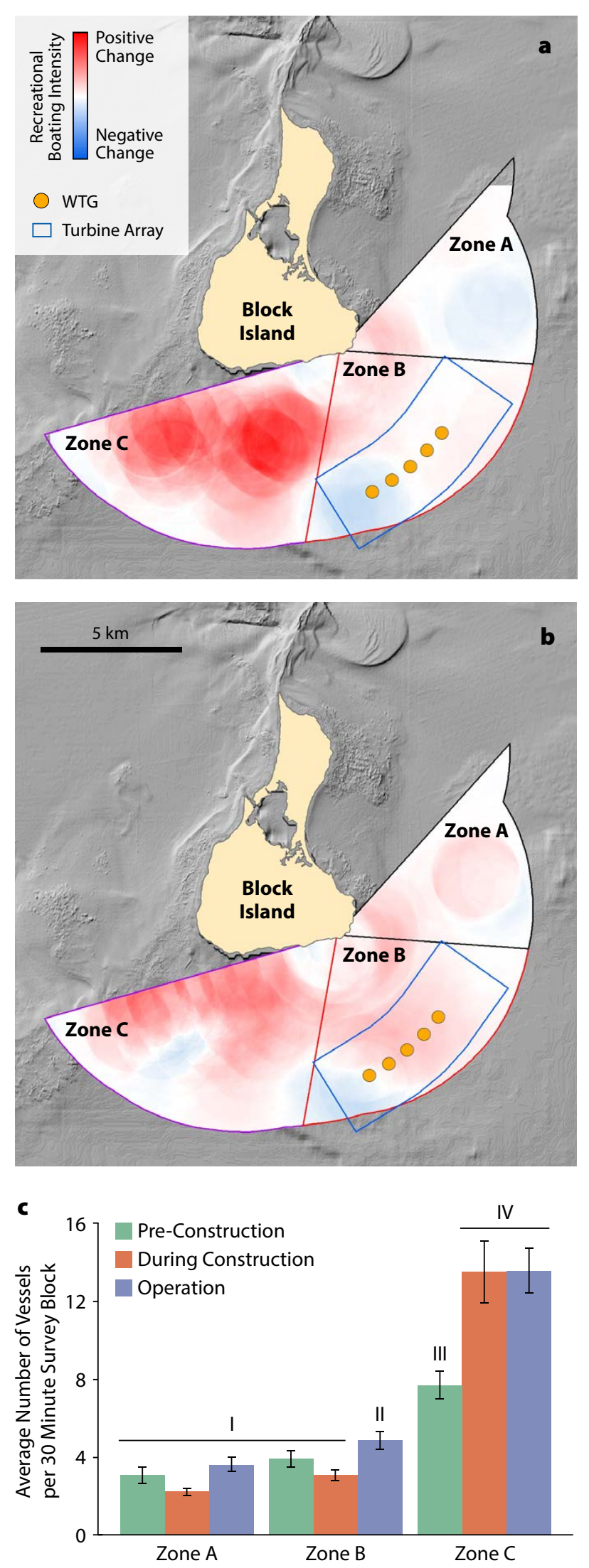

FIGURE 6. Comparison of recreational boating intensity observed: (a) pre-construction (2015) to construction (2016), and (b) preconstruction (2015) to operation (2017, 2019). WTG dots denote the locations of wind turbines. Boxes outlined in blue encompass the turbine array. (c) Notations of I, II, III, and IV indicate significant differences between groups. sight, extending the survey an additional month would have more fully captured the seasonal migration patterns of lobsters in the areas sampled, and would have provided another month for evaluation of the Phase II construction period.

\section{RECREATIONAL BOATING}

Block Island has extensive recreational boating activities that include sailing regattas, diving, and recreational fishing (RICRMC, 2010; Smythe et al., 2016). The importance of these activities and the potential for disruption led RICRMC to require recreational boating surveys before, during, and after construction, scheduled for peak boating weekends, as part of the approval for the project (RICRMC, 2010). Because the BIWF is located close to natural reefs and OSW structures can function as artificial reefs, determining the response of recreational fishing activity to new structure was an important goal of the survey (Wilhelmsson and Malm, 2008). The location of turbine structures within $5.3 \mathrm{~km}$ of Block Island allowed visual surveys from a fixed location onshore to assess recreational boating activities.

\section{Recreational Boating Sampling Design}

Six point-count surveys of recreational boating were conducted in June and July during pre-construction, construction, and operation time periods (Sabo et al., 2020; Table 1). For each survey, a single observer recorded vessels from a single vantage point during four 30-minute survey blocks in the morning, afternoon, and evening over the course of approximately one week. In addition to vessel activity (fishing, transiting, diving, other), vessel locations were recorded to explore spatial patterns of recreational boating intensity. The field of view was divided into three spatial zones separating the APE from adjacent areas (Figure 2). Zone A included part of the East Grounds fishing area, Zone B included the APE and Southeast Ledge, and Zone C covered most of Southwest Ledge, a popular recreational fishing and diving area.

\section{Recreational Boating Analytical Methods}

Vessel count data were grouped by project phase using the 30-minute survey block as the observational unit with variable level of effort among time periods (Table 1). Vessel counts were modeled as a function of project phase and spatial zone using Poisson GLMs and a log-link. Post-hoc comparisons were conducted to determine which groups were significantly different from one another (Tukey's test, familywise $\alpha=0.05$ ). The Point Density Spatial tool (ESRI ArcMap) was used to calculate and plot the density of vessels across the survey area (vessels per square mile). Vessel densities were normalized by the level of effort. Direct pairwise comparisons of the spatial distribution of vessel density between pre-construction and during construction as well as pre-construction and operation were visualized (Figure 6).

Recreational fishing motorboats were overwhelmingly the most frequently observed vessel activity and type during the study. Over $91 \%$ of the observations of approximately 4,700 ves- 
sels were identified as a fishing vessel in transit or actively fishing. The number of vessels observed in Zones $A$ and $B$ were consistent among time periods, with the exception of a significant $40 \%$ increase in Zone B during operation (Figure 6). However, there was a significant increase $(75 \%)$ in recreational boating intensity in Zone $\mathrm{C}$ (natural reef, located west of the turbines) during construction and operation compared to pre-construction (Figure 6).

Vessel traffic in Zone B was intensely clustered around Southeast Ledge during pre-construction and more evenly distributed among the turbine array during operation. Boating activity increased in intensity and spatial extent in all areas during operation (Figure 6b). Observations of increased boating activity around the turbines are consistent with reports of recreational fishermen targeting black sea bass, scup, and summer flounder in this area and consistent with higher black sea bass catches in the demersal trawl survey during operation (Figure 4). The greater increase in recreational fishing activity in Zone $\mathrm{C}$ during operation may reflect targeting different species that use natural reefs.

\section{Lessons Learned from Recreational} Boating Sampling Design

Rather than interviews or anecdotal reports, the study design used a unique attribute of the BIWF-visibility from shore-to conduct direct observations of boating activity. The sampling periods were defined by boating organizations, but not by the heaviest usersrecreational fishermen. As a result, periods of potentially heavy use by fishermen may not have been sampled. Despite this limitation, results from one-week surveys during high summer use revealed that recreational fishermen are the primary users of the area surrounding the BIWF. Most of this activity was concentrated in several regions with valuable fish habitat. The area has experienced a spatial shift in fishing activity consistent with use of the turbine foundations as available hard structure, but recreational fishermen still fished in higher numbers at the adjacent natural rock reefs. These results inform planning for effects of OSW in areas with active recreational fishing targeting natural reefs. It is widely reported mated to increase decapod abundances in areas where $\mathrm{HBH}$ is limited (Krone et al., 2017). These findings may not translate well to lobster and crab fisheries in portions of the US Atlantic because several planned wind farms occur in areas with

\section{Lessons learned included practical guidance, for example, for collaborating with stakeholders and regional scientists to address concerns through adaptive monitoring, quantifying uncertainty associated with $\mathrm{BACl}$ contrasts, and evaluating the duration of a seasonal lobster survey.}

that recreational fishermen benefit from OSW structures at the BIWF (ten Brink and Dalton, 2018), but effects on use of natural reefs have not been reported; these anecdotal reports can be verified with on-site surveys and compared with appropriate biological sampling.

\section{DISCUSSION}

The suite of monitoring studies conducted at the BIWF related to fishing resources provides a comprehensive and informative assessment of wind farm effects that can be built upon for future efforts. The creation of monitoring plans and research studies on the effects of US OSW development on fish and fisheries has been largely ad hoc and project-specific (NASEM, 2018). The primary practice has been to examine results of OSW studies in Europe and poll user groups on data gaps. However, extrapolating European study results to US OSW projects is likely to prove unreliable (Lindeboom et al., 2015) because of differences between the US Atlantic and European waters. In Europe, fishing limitations within wind farms create de facto marine protected areas that, for example, increase lobster productivity (Roach et al., 2018). Introduction of hard substrata is esti-
$\mathrm{HBH}$, and fishery closures are not anticipated. The challenge of developing fisheries monitoring plans and research for US OSW may best be informed by collaborative arrangements with local fishermen (sensu Stephenson et al., 2016) and a critical examination of relevant local conditions (e.g., habitats, populations, scale) in the broader context of longer-term results from Europe.

\section{CONCLUSIONS AND LESSONS LEARNED}

The design and execution of the BIWF monitoring studies produced substantive results while revealing important lessons about site assessment and monitoring (Box 1). Both soft and hard bottom habitats were present close to the BIWF, and construction effects were identified in both hard (Guarinello and Carey, 2020) and soft bottoms using directed visual and MBES surveys (HDR, 2018). Future surveys should include longer-term assessments of recovery of relocated boulders and of connectivity between introduced hard substrata (turbine foundations) and natural reefs.

The engagement of fishermen in cooperative research studies of demersal and epibenthic species (both commercially 


\section{BOX 1. KEY LESSONS FOR FUTURE OFFSHORE WIND FARM BIOLOGICAL MONITORING}

1

Collaborate with the fishing industry and regional scientists to ensure sampling methodology is consistent with industry practices and existing surveys so that study results can be assessed in a regional context.

2 Quantify the magnitude of change (with uncertainty), and don't rely solely on statistical significance to demonstrate a wind farm effect.

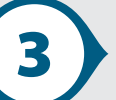

Include metrics other than catch rates for fish (diet composition, condition, and stomach fullness) and lobsters (shell disease, ovigery rates, and cull status), which may be more sensitive indicators of potential effects.

\section{Conduct adaptive monitoring in response to stakeholder concerns and} early results.

5 Maximize data collection on bycatch species with potential importance to commercial or recreational fisheries.

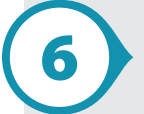

Use a before-after-gradient design when interested in fine-scale effects, such as enrichment.

To assess effects of construction on marine habitat, utilize directed visual assessment tools and high-resolution MBES mapping, and stratify sampling based on physical habitat stability.

important species and bycatch) established approaches that produced results and lessons for future OSW monitoring. Notably, collecting data that are compatible with historical and ongoing regional surveys provides much-needed context for evaluating study results. Comparisons of BIWF survey results to other regional studies were required to evaluate whether observations made during wind farm operation reflected an effect that may have included reference locations or were part of a broader regional trend, including effects on behavioral and physiological traits not apparent from analysis of catch rates alone. For assessment of fine-scale effects with clear spatial gradients, such as responses to near-turbine benthic enrichment, before-after-gradient designs may have greater power (Methratta, 2020). Recognizing cases in which confidence intervals were broad also provides valuable information about whether the level of effort for, and the design of, these surveys were sufficient to detect changes of interest. However, guidance from regulatory agencies and stakeholders as to what level of change in catch is meaningful is lacking but greatly needed to improve future OSW survey designs. From residual variance for the dominant species in this study, the relationship between detectable effect sizes and level of effort may be estimated and used to inform future monitoring for Atlantic Coast OSW projects. Additionally, the value of alternative designs may be investigated, for example, the monthly, seven-year time series may be subsampled for variance estimates from less frequent sampling. Beyond statistical significance lies the more important and difficult question, which is: what constitutes a biologically meaningful difference?

European monitoring of OSW development has provided valuable guidance for design of US assessments (Lindeboom et al., 2015; Degraer et al., 2018; Dannheim et al., 2020). As the US OSW industry matures and moves from pilot- to utility-scale wind projects, assessment and monitoring of potential effects on marine resources will need to address the full "sphere of influence" (sensu Degraer et al., 2018) on both highly local (turbine) and regional ecosystem scales (Dannheim et al., 2020). These results provide a good starting point for US OSW studies and build upon decades of European experience. @

\section{REFERENCES}

ASMFC (Atlantic States Marine Fisheries Commission). 2015. American Lobster Benchmark Stock Assessment and Peer Review Report. Prepared by the ASMFC American Lobster Stock Assessment Review Panel, June 8-11, 2015, Woods Hole, MA 438 pp., https://www.asmfc.org/ uploads/file//55d61d73AmLobsterStockAssmt PeerReviewReport_Aug2015_red2.pdf.

Bonzek, C.F., J. Gartland, D.J. Gauthier, and R.J. Latour. 2017. Northeast Area Monitoring and Assessment Program (NEAMAP) Data collection and analysis in support of single and multispecies stock assessments in the Mid-Atlantic: Northeast Area Monitoring and Assessment Program Near Shore Trawl Survey. Virginia Institute of Marine Science, William \& Mary, 338 pp., https://doi.org/ 10.25773/7206-KM61.

Castro, K.M., and B.A. Somers. 2012. Observations of epizootic shell disease in American lobsters, Homarus americanus, in southern New England. Journal of Shellfish Research 31:423-430, https://doi.org/10.2983/035.031.0202.

Chevalier, M., J.C. Russell, and J. Knape. 2019. New measures for evaluation of environmental perturbations using Before-After-Control-Impact analyses. Ecological Applications 29:e01838, https://doi.org/ 10.1002/eap.1838.

Clarke, K.R., R.N. Gorley, P.J. Somerfield, and R.M. Warwick. 2014. Change in Marine Communities: An Approach to Statistical Analysis and Interpretation, 2nd ed. PRIMER-E, Plymouth, United Kingdom, 176 pp.

Dannheim, J., L. Bergström, S.N.R. Birchenough, R. Brzana, A.R. Boon, J.W.P. Coolen, J.C. Dauvin, I. De Mesel, J. Derweduwen, A.B. Gill, and others. 2020. Benthic effects of offshore renewables: Identification of knowledge gaps and 
urgently needed research. ICES Journal of Marine Science 77(3):1,092-1,108, https://doi.org/10.1093/ icesjms/fsz018.

Degraer, S., R. Brabant, B. Rumes, and L. Vigin, eds. 2018. Environmental Impacts of Offshore Wind Farms in the Belgian Part of the North Sea: Assessing and Managing Effect Spheres of Influence. Royal Belgian Institute of Natural Sciences, OD Natural Environment, Marine Ecology and Management, Brussels, $136 \mathrm{pp}$.

FGDC (Federal Geographic Data Committee). 2012. Coastal and Marine Ecological Classification Standard. FGDC-STD-018-2012, Reston, VA 353 pp., https://www.fgdc.gov/standards/projects/ cmecs-folder/CMECS_Version_06-2012_FINAL.pdf.

Goldstein, J.S., and W.H. Watson III. 2015. Seasonal movements of American lobsters in southern Gulf of Maine coastal waters: Patterns, environmental triggers, and implications for larval release. Marine Ecology Progress Series 524:197-211, https://doi.org/10.3354/meps11192.

Gotceitas, V., and J.A. Brown. 1993. Substrate selection by juvenile Atlantic cod (Gadus morhua): Effects of predation risk. Oecologia 93:31-37, https://doi.org/10.1007/BF00321187.

Griswold, C.A., and J. Prezioso. 1981. In-situ observations on reproductive behavior of the long-finned squid, Loligo pealei. Fisheries Bulletin 78:945-947.

Guarinello, M.L., D.A. Carey, and L.B. Read. 2017. Hard Bottom Post-Construction Surveys Year 1 Report for 2016 Summer Post-Construction Surveys to Characterize Potential Impacts and Response of Hard Bottom Habitats to Anchor Placement at the Block Island Wind Farm (BIWF). Prepared for Deepwater Wind Block Island LLC, Providence, RI, $31 \mathrm{pp}$.

Guarinello, M.L., and D.A. Carey. 2020. Methodologies for assessing moraine habitats for offshore wind construction developed at the Block Island Wind Farm. Estuaries and Coasts, https://doi.org/ 10.1007/s12237-020-00818-w.

Guida, V., A. Drohan, H. Welch, J. McHenry, D. Johnson, V. Kentner, J. Brink, D. Timmons, and E. Estela-Gomez. 2017. Habitat Mapping and Assessment of Northeast Wind Energy Areas. U.S. Department of the Interior, Bureau of Ocean Energy Management, Sterling, VA, OCS Study BOEM 2017-088, 312 pp.

HDR. 2018. Field Observations During Wind Turbine Foundation Installation at the Block Island Wind Farm, Rhode Island. Final Report to the US Department of the Interior, Bureau of Ocean Energy Management, Office of Renewable Energy Programs, OCS Study BOEM 2018-029, 175 pp.

HDR. 2020. Benthic and Epifaunal Monitoring During Wind Turbine Installation and Operation at the Block Island Wind Farm, Rhode Island. Project Report. Final Report to the US Department of the Interior, Bureau of Ocean Energy Management, Office of Renewable Energy Programs, https://espis.boem.gov/final reports/BOEM_ 2020-044.pdf.

Krone, R., G. Dederer, P. Kanstinger, P. Krämer, C. Schneider, and I. Schmalenbach. 2017. Mobile demersal megafauna at common offshore wind turbine foundations in the German Bight (North Sea) two years after deployment-increased production rate of Cancer pagurus. Marine Environmental Research 123:53-61, https://doi.org/10.1016/ j.marenvres.2016.11.011.

Lindeboom, H., S. Degraer, J. Dannheim, A. Gill, and D. Wilhelmsson. 2015. Offshore wind park monitoring programmes, lessons learned and recommendations for the future. Hydrobiologia 756:169-180, https://doi.org/10.1007/s10750-015-2267-4.

Methratta, E.T. 2020. Monitoring fishery resources at offshore wind farms: BACl vs. BAG designs. ICES Journal of Marine Science, https://doi.org/10.1093/ icesjms/fsaa026.
NASEM (National Academies of Sciences, Engineering, and Medicine). 2018. Atlantic Offshore Renewable Energy Development and Fisheries: Proceedings of a Workshop-In Brief. The National Academies Press, Washington, DC, 12 pp., https://doi.org/10.17226/25062.

R Core Team. 2019. R: A Language and Environment for Statistical Computing. R Foundation for Statistical Computing, Vienna, Austria, http://www.R-project.org.

Rhode Island Coastal Resources Management Council (RICRMC). 2010. Rhode Island Ocean Special Area Management Plan Volume 1. Adopted by the Rhode Island Coastal Resources Management Council October 19, 2010.

Roach, M., M. Cohen, R. Forster, A.S. Revill, and M. Johnson. 2018. The effects of temporary exclusion of activity due to wind farm construction on a lobster (Homarus gammarus) fishery suggests a potential management approach. ICES Journal of Marine Science 75:1,416-1,426, https://doi.org 10.1093/icesjms/fsy006.

Russell, A., J. Firestone, D. Bidwell, and M. Gardner. 2020. Place meaning and consistency with offshore wind: An island and coastal tale. Renewable and Sustainable Energy Reviews 132:110044, https://doi.org/10.1016/j.rser.2020.110044.

Sabo, S., A. Murphy, and D. Carey. 2020. Block Island Wind Farm Recreational Boating Survey PostConstruction Year 2019 Annual Report and Project Synthesis April 2020. Prepared for Deepwater Wind Block Island, LLC, Providence, RI, 42 pp.

Schad, D.J., S. Vasishth, S. Hohenstein, and R. Kliegl. 2020. How to capitalize on a priori contrasts in linear (mixed) models: A tutorial. Journal of Memory and Language 110:104038, https://doi.org/10.1016/ j.jml.2019.104038

Smith, E.P., D.R. Orvos, and J. Cairns. 1993. Impact assessment using the before-after-controlimpact (BACl) model: Concerns and comments. Canadian Journal of Fisheries and Aquatic Sciences 50:627-637, https://doi.org/10.1139/ f93-072.

Smith, H., T. Smythe, A. Moore, D. Bidwell, and J. McCann. 2018. The social dynamics of turbine tourism and recreation: Introducing a mixedmethod approach to the study of the first U.S. offshore wind farm. Energy Research \& Social Science 45:307-317, https://doi.org/10.1016/ j.erss.2018.06.018.

Smith, K., and T. McNeilan. 2011. Seabed Scour Considerations for Offshore Wind Energy Development in the Atlantic OCS, Technology Assessment and Research Study No. 656. Prepared for the Bureau of Ocean Energy Management, Washington, DC.

Smythe, T., N. Andrescavage, and C. Fox. 2016. The Rhode Island Ocean Special Area Management Plan, 2008-2015: From Inception through Implementation. Case Studies of Marine Spatial Planning Report Series, J. McCann, ed., Coastal Resources Center and Rhode Island Sea Grant College Program, URI Graduate School of Oceanography, Narragansett, RI, 80 pp.

Stephenson, R.L., S. Paul, M.A. Pastoors, M. Kraan, P. Holm, M. Wiber, S. Mackinson, D.J. Dankel, K. Brooks, and A. Benson. 2016. Integrating fishers' knowledge research in science and management. ICES Journal of Marine Science 73(1):459-465, https://doi.org/10.1093/icesjms/fsw025.

Stewart-Oaten, A., and J.R. Bence. 2001. Temporal and spatial variation in environmental impact assessment. Ecological Monographs 71:305-339, https://doi.org/10.1890/0012-9615(2001)07110305: TASVIE]2.0.CO;2.

ten Brink, T.S., and T. Dalton. 2018. Perceptions of commercial and recreational fishers on the potential ecological impacts of the Block Island Wind Farm (US). Frontiers in Marine Science 5:1-13, https://doi.org/10.3389/fmars.2018.00439.
Underwood, A.J. 1992. Beyond BACl: The detection of environmental impacts on populations in the real, but variable, world. Journal of Experimental Marine Biology and Ecology 161:145-178,

https://doi.org/10.1016/0022-0981(92)90094-Q.

Wahle, R.A., and R.S. Steneck. 1991. Recruitment habitats and nursery grounds of the American lobster Homarus americanus: A demographic bottleneck? Marine Ecology Progress Series 69:231-243, https://doi.org/10.3354/meps069231.

Wilber, D., L. Read, M. Griffin, and D. Carey. 2020a. Block Island Wind Farm Demersal Fish Trawl Survey Synthesis Report Years 1 to 6, October 2012 through September 2018. Technical report prepared for Deepwater Wind Block Island LLC, Providence, RI, 80 pp.

Wilber, D., L. Read, M. Griffin, and D. Carey. 2020b. Block Island Wind Farm Ventless Trap Lobster Survey Synthesis Report 2013-2018. Technical report prepared for Deepwater Wind Block Island LLC, Providence, RI, 62 pp.

Wilhelmsson, D., and T. Malm. 2008. Fouling assemblages on offshore wind power plants and adjacent substrata. Estuarine Coastal and Shelf Science 79(3):459-466, https://doi.org/10.1016/ j.ecss.2008.04.020.

\section{ACKNOWLEDGMENTS}

The authors thank E. Bellagamba Fucile for editing, Andy Lipsky for support on engagement, and Aileen Kenney for support of these studies. Funding was provided by Deepwater Wind Block Island. Special thanks to our commercial fishing partners Rodman Sykes, Bill McElroy, and Lanny Dellinger for meeting the challenge of conducting seven years of research on the effects of BIWF on commercial finfish and shellfish.

\section{AUTHORS}

Drew A. Carey (drew@inspireenvironmental.com) is Principal Scientist and Dara H. Wilber is Senior Scientist, both at INSPIRE Environmental, Newport, RI, USA. Lorraine B. Read is Senior Statistician, Exa Data and Mapping, Poulsbo, WA, USA. Marisa L. Guarinello is Senior Scientist, INSPIRE Environmental, Newport, RI, USA. Matthew Griffin is Scientist, Saltbox Sea Farm, North Kingstown, RI, USA. Steven Sabo is Staff Scientist, INSPIRE Environmental, Newport, RI, USA

\section{ARTICLE CITATION}

Carey, D.A., D.H. Wilber, L.B. Read, M.L. Guarinello, M. Griffin, and S. Sabo. 2020. Effects of the Block Island Wind Farm on coastal resources: Lessons learned. Oceanography 33(4):70-81, https://doi.org/ 10.5670/oceanog.2020.407.

\section{COPYRIGHT \& USAGE}

This is an open access article made available under the terms of the Creative Commons Attribution 4.0 International License (https://creativecommons.org/ licenses/by/4.0/), which permits use, sharing, adaptation, distribution, and reproduction in any medium or format as long as users cite the materials appropriately, provide a link to the Creative Commons license, and indicate the changes that were made to the original content. 